\title{
2. Aterosclerosis y dislipidemias
}

\subsection{Ultrasonido carotídeo en artritis psoriásica: un estudio de casos y controles}

Azpiri López José Ramón, Garza Acosta Andrea Cecilia, Guajardo Jáuregui Natalia, Loya Acosta Julieta, Pérez Villar Alejandra, Colunga Pedraza Iris Jazmín, Galarza Delgado Dionicio Ángel Hospital Universitario «Dr. José Eleuterio González».

Tipo de estudio: Estudio pronóstico

Introducción: Los pacientes con artritis psoriásica (APs) tienen un mayor riesgo cardiovascular (RCV). El ultrasonido carotídeo (USc) nos permite medir el grosor íntima-media carotídeo (GIMc) así como la detección de placa carotídea (PC), es una herramienta no invasiva útil en la detección de la aterosclerosis subclínica. Objetivo: Comparar las características del ultrasonido carotídeo en pacientes con APs y controles. Metodología: Se incluyeron 69 pacientes con APs y 69 controles pareados por edad y comorbilidades. El aumento del GIMc se definió como $\geq 0.9 \mathrm{~mm}$ y la PC como un estrechamiento focal $\geq 0.5 \mathrm{~mm}$ de la luz o un GIMc $\geq 1.2 \mathrm{~mm}$. El análisis descriptivo fue realizado con frecuencias (\%) y mediana (q25-q75) y comparaciones con $\chi^{2}$. Se consideró significativa una $p<0.05$. Resultados: Se incluyeron un total de 138 sujetos. Las características clínicas y demográficas se muestran en la Tabla 2.1.1. El aumento de GIMc tuvo mayor prevalencia en los pacientes con APs que en los controles ( $p=$ $0.017)$. No se encontraron diferencias en la prevalencia de la PC entre los pacientes con APs y el grupo control (Tabla 2.1.2). Discusión y conclusiones: Los pacientes con APs tienen un mayor RCV, demostrado con el aumento de la prevalencia del GIMc. Por lo tanto, es recomendado realizar USc para lograr un manejo integral.

Tabla 2.1.2: Hallazgos en ultrasonido carotídeo.

\begin{tabular}{lccc} 
& $\begin{array}{c}\text { APs } \\
(\mathbf{n}=\mathbf{6 9})\end{array}$ & $\begin{array}{c}\text { Controles } \\
\mathbf{( n = 6 9 )}\end{array}$ & \\
Variable & $\mathbf{n}(\mathbf{\%})$ & $\mathbf{n}(\mathbf{\%})$ & $\mathbf{p}$ \\
\hline Placa carotídea & $27(39.1)$ & $17(24.6)$ & NS \\
Aumento del GIMc & $9(13.0)$ & $1(1.4)$ & 0.017 \\
\hline
\end{tabular}

APs = artritis psoriásica; GIMc = grosor íntima-media carotídeo; $\mathrm{NS}=$ no significativa.

Tabla 2.1.1: Características clínicas y demográficas.

\begin{tabular}{|c|c|c|c|}
\hline & $\begin{array}{c}\text { APs }(\mathrm{n}=69) \\
n(\%)\end{array}$ & $\begin{array}{c}\text { Controles }(n=69) \\
n(\%)\end{array}$ & p \\
\hline Edad, media \pm DE & $53.58 \pm 10.94$ & $53.86 \pm 7.31$ & NS \\
\hline Mujeres & $38(55.1)$ & $59(85.5)$ & $<0.001$ \\
\hline Obesidad & $26(37.7)$ & $28(40.6)$ & NS \\
\hline Diabetes mellitus tipo 2 & $14(20.3)$ & $9(13.0)$ & NS \\
\hline Hipertensión arterial & $27(39.1)$ & $19(27.5)$ & NS \\
\hline Dislipidemia & $29(42.0)$ & $24(34.8)$ & NS \\
\hline Tabaquismo activo & $15(21.7)$ & $12(17.4)$ & NS \\
\hline Duración de la enfermedad, media (q25-q75) & $5(2.5-8)$ & - & - \\
\hline Metotrexato & $46(66.7)$ & - & - \\
\hline Biológicos & $23(33.3)$ & - & - \\
\hline DAS28-VSG, media \pm DE & $3.74 \pm 1.477$ & - & - \\
\hline DAS28-PCR, media \pm DE & $2.43 \pm 1.088$ & - & - \\
\hline DAPSA, media (q25-q75) & $35(27.5-58.5)$ & - & - \\
\hline
\end{tabular}

APs = artritis psoriásica; DAS28-VSG = Puntuación para la actividad de la enfermedad (por sus siglas en inglés)-velocidad de sedimentación globular; DAS28-PCR = Puntuación para la actividad de la enfermedad (por sus siglas en inglés)-proteína C reactiva; DAPSA = actividad de la enfermedad para la artritis psoriásica (por sus siglas en inglés); NS = no significativa. 